\title{
A facile method for the preparation of Covalent Triazine Framework coated monoliths as catalyst support - applications in C1 catalysis
}

Anastasiya V. Bavykina, Alma Itzel Olivos Suarez, Dmitrii Osadchii, Rahul

Valecha, Robert Franz, Michiel Makkee, Freek Kapteijn, and Jorge Gascon

ACS Appl. Mater. Interfaces, Just Accepted Manuscript • DOI: 10.1021/acsami.7b07339 • Publication Date (Web): 17 Jul 2017

Downloaded from http://pubs.acs.org on July 23, 2017

\section{Just Accepted}

"Just Accepted" manuscripts have been peer-reviewed and accepted for publication. They are posted online prior to technical editing, formatting for publication and author proofing. The American Chemical Society provides "Just Accepted" as a free service to the research community to expedite the dissemination of scientific material as soon as possible after acceptance. "Just Accepted" manuscripts appear in full in PDF format accompanied by an HTML abstract. "Just Accepted" manuscripts have been fully peer reviewed, but should not be considered the official version of record. They are accessible to all readers and citable by the Digital Object Identifier (DOI®). "Just Accepted" is an optional service offered to authors. Therefore, the "Just Accepted" Web site may not include all articles that will be published in the journal. After a manuscript is technically edited and formatted, it will be removed from the "Just Accepted" Web site and published as an ASAP article. Note that technical editing may introduce minor changes to the manuscript text and/or graphics which could affect content, and all legal disclaimers and ethical guidelines that apply to the journal pertain. ACS cannot be held responsible for errors or consequences arising from the use of information contained in these "Just Accepted" manuscripts. 


\title{
A facile method for the preparation of Covalent
}

\section{Triazine Framework coated monoliths as catalyst}

\section{support - applications in $\mathrm{C} 1$ catalysis}

\author{
Anastasiya V. Bavykina, ${ }^{* \dagger+}$ Alma I. Olivos-Suarez, ${ }^{\dagger}$ Dmitrii Osadchii, ${ }^{\dagger}$ Rahul Valecha, ${ }^{\dagger}$ Robert \\ Franz, ${ }^{\dagger}$ Michiel Makkee, ${ }^{\dagger}$ Freek Kapteijn, ${ }^{\dagger}$ and Jorge Gascon ${ }^{*}+$, \\ ${ }^{\dagger}$ Delft University of TechnologyFaculty of Applied Sciences, Chemical Engineering \\ Building 58, Van der Maasweg 9 2629HZ, Delft, The Netherlands \\ ${ }^{\ddagger}$ King Abdullah University of Science and Technology, KAUST Catalysis Center, Advanced \\ Catalytic Materials
}

Thuwal 23955, Saudi Arabia

\begin{abstract}
KEYWORDS. covalent triazine frameworks, structured catalysts, methane, methanol, hydrogen
ABSTRACT. A quasi Chemical Vapour Deposition method for the manufacturing of welldefined Covalent Triazine Framework (CTF) coatings on cordierite monoliths is reported. The resulting supported porous organic polymer is an excellent support for the immobilisation of two different homogeneous catalysts: 1) an $\operatorname{Ir}^{\mathrm{III}} \mathrm{Cp}^{*}$-based catalyst for the hydrogen production from
\end{abstract}


formic acid, and 2) a $\mathrm{Pt}^{\mathrm{II}}$-based for the direct activation of methane via Periana chemistry. The immobilised catalysts display a much higher activity in comparison with the unsupported CTF operated in slurry because of improved mass transport. Our results demonstrate that CTF based catalysts can be further optimised by engineering at different length-scales.

\section{Introduction}

Covalent Triazine Frameworks (CTFs) are a class of porous polymers synthesised through the trimerisation of aromatic nitriles. ${ }^{1-2}$ Over the past few years CTFs have been proposed for a wide range of applications. ${ }^{3-4}$ For instance, due to their high nitrogen content, as candidates for $\mathrm{CO}_{2}$ capture and separation, ${ }^{5-7}$ while their fully conjugated nature offers new possibilities in electro- ${ }^{8-}$ 10 and photocatalysis. ${ }^{11-12}$ In addition, CTFs have shown to bear excellent properties as supports for single site organometallic catalysts. This application holds a large promise owing to the free quasi-bipyridine moieties present within the framework, allowing coordination of a large array of organometallic compounds. ${ }^{13-18}$

The high stability of CTFs is, to large extent, related to the harsh conditions under which these materials are synthesised (excess of $\mathrm{ZnCl}_{2}$ as a trimerisation catalyst at $500^{\circ} \mathrm{C}$ ). Such extreme synthesis conditions usually lead to an ill-defined CTF powder that consist of large agglomerates of up to tens of micrometers in size. Such poorly defined particles are obviously not ideal for application in catalysis, especially when targeting liquid-phase reactions in stirred tank reactors. On one hand, loss of material as a result of attrition of the agglomerates makes catalyst recycling cumbersome. On the other hand, large particles, even when resulting from the agglomeration of smaller units, may impose serious diffusion limitations and, therefore, poor catalyst utilisation. Moreover, the complex hydrodynamics of slurries in stirred tank reactors makes scale-up 
difficult and can lead to problems like poor suspension of particles and a non-uniform distribution of catalyst. In our recent work, we addressed the first issue by formulating CTF/polymer spherical composites. The obtained spheres showed high stability and recyclability during several catalytic runs. ${ }^{14}$ However, CTF's porosity could not be completely preserved upon formulation. Moreover, the use of polymers as binders limits the application of the resulting composites to reaction media in which the polymeric component would not dissolve. In the present work, we demonstrate that both issues can be addressed by CTF structuring, using a monolith as a support. Due to the unusual synthesis conditions, we have developed a new manufacturing protocol for the polymerisation of CTFs, directly on the surface of a cordierite monolith. This method, which can be described as a quasi Chemical Vapour Deposition, is a straightforward approach that renders a very uniform and thin CTF coating. These coatings are stable, easy to handle, and can be used in the same way as the parent material to coordinate metal complexes. A comparison between the performance of the monolith-supported CTF and powderform $\mathrm{CTF}$ after incorporation of the catalysts (i.e. IrCp* or $\mathrm{Pt}$, vide infra) clearly demonstrates the superior performance of the former, attributed to the better mass transport properties of the thin layers coated on the monolith channels.

\section{Experimental Section}

\subsection{Micro-CTF synthesis.}

To synthesise micro-CTF, a glass ampoule was charged with 2,6-pyridinedicarbonitrile $(0.124$ $\mathrm{g}, 0.96 \mathrm{mmol})$ and anhydrous $\mathrm{ZnCl}_{2}(0.664 \mathrm{~g}, 4.8 \mathrm{mmol})$ in a glovebox. The ampoule was flame sealed and the mixture was heated at $500^{\circ} \mathrm{C}$ for $48 \mathrm{~h}$ and then cooled to room temperature. The product was consecutively washed in $5 \mathrm{M} \mathrm{HCl}$ at $100^{\circ} \mathrm{C}$, in $\mathrm{NH}_{4} \mathrm{OH}$ at $60^{\circ} \mathrm{C}$, in $\mathrm{H}_{2} \mathrm{O}$ at $100^{\circ} \mathrm{C}$ and then in THF at $60^{\circ} \mathrm{C}$, each step overnight. The washing steps might seem excessive, but were, as 
we found, required to remove $\mathrm{ZnCl}_{2} .200 \mathrm{ml}$ of each solvent was used for the washing procedure. Finally, the powder was dried in vacuum at $180^{\circ} \mathrm{C}$ overnight.

\subsection{Meso-CTF synthesis}

The synthesis procedure is identical to the one of micro-CTF with a different ampoule loading: 2,6-pyridinedicarbonitrile $(0.041 \mathrm{~g}, 320 \mu \mathrm{mol}), 4,4$ '-biphenyldicarbonitrile $(0.131 \mathrm{~g}, 640 \mu \mathrm{mol})$, and anhydrous $\mathrm{ZnCl}_{2}(0.664 \mathrm{~g}, 4.8 \mathrm{mmol})$. The yield for both micro- and meso-CTF was 90\%.

\subsection{Monolith Coating}

For the coating with CTF, 600 cpsi (cells per square inch) monoliths were used having the following characteristics: channel diameter $0.93 \mathrm{~mm}$, wall thickness $0.11 \mathrm{~mm}$, open frontal area $80 \%$, wall porosity 0.33 ). The monolith pieces were cut down to a suitable size (around $1 \mathrm{~cm}$ long and 0.4 and $0.5 \mathrm{~cm}$ height and width, respectively).

In order to prepare the micro-CTF coated monolith, the monolith cut was dipped in a solution of $0.6 \mathrm{~g}$ 2,6-bipyridinedicarbonitrile and $1.7 \mathrm{~g}$ anhydrous $\mathrm{ZnCl}_{2}$ in $5 \mathrm{~mL}$ acetone. For the preparation of the meso-CTF coated monolith, a cordierite monolith piece was dipped in a solution of $0.6 \mathrm{~g}$ 2,6-bipyridinedicarbonitrile, $1.9 \mathrm{~g}$ 4,4-biphenyldicarbonitrile and $1.7 \mathrm{~g}$ anhydrous $\mathrm{ZnCl}_{2}$ in $5 \mathrm{ml}$ acetone. In both cases the monolith was stirred overnight in the solution at room temperature. Following this step, the acetone solution wetted (impregnated) support was dried at $60{ }^{\circ} \mathrm{C}$ overnight. Next, the monolith was placed in a glass ampoule, evacuated and flame sealed and subjected into an oven to the following temperature program: heating rate $1{ }^{\circ} \mathrm{C} \min ^{-1}$ $500^{\circ} \mathrm{C}$ for $10 \mathrm{~h}-$ cooling rate $0.16^{\circ} \mathrm{C} \mathrm{min}^{-1}$. The coated monolith was then washed with $50 \%$ $\mathrm{HCl}$ overnight at $100^{\circ} \mathrm{C}$. Following this, it was subsequently washed with $50 \% \mathrm{NH}_{4} \mathrm{OH}$ at $50^{\circ} \mathrm{C}$ overnight, with water overnight at $100^{\circ} \mathrm{C}$, and finally with tetrahydrofuran (THF) at $50^{\circ} \mathrm{C}$ overnight. The washed monolith was vacuum dried at $180{ }^{\circ} \mathrm{C}$. This washing procedure was 
optimised in a previous work to remove as much $\mathrm{Zn}$ from the material as possible. The resulting CTF coatings are shown in Figure 1.

\subsection{Preparation of Ir@CTF@monolith}

Firstly, a solution of $0.01 \mathrm{~g}\left[\mathrm{IrCp}^{*} \mathrm{Cl}_{2}\right]_{2}$ in $60 \mathrm{~mL} \mathrm{H} \mathrm{H}_{2} \mathrm{O}$ was prepared. Next, the CTF-coated monolith was stirred overnight in this solution at room temperature. Following this, the Ir exchanged monolith was washed in a mixture of $30 \mathrm{~mL}$ water, $30 \mathrm{~mL}$ DMF and $0.28 \mathrm{~g}$ trifluoromethanesulfonic acid (HOTf) at a temperature of $50{ }^{\circ} \mathrm{C}$ overnight in order to remove the $\mathrm{Cl}^{-}$ions, and exchange the $\mathrm{Cl}^{-}$ions by the weakly coordinated OTf. Subsequently, the monolith was washed with $50 \mathrm{ml}$ water at $50{ }^{\circ} \mathrm{C}$ overnight. Finally, the $\mathrm{Ir}$ loaded monolith was vacuum dried at $60{ }^{\circ} \mathrm{C}$ overnight. Coordination of Ir to the powder was performed as described elsewhere ${ }^{13-14}$ with an altered Ir loading $\left(1 \mathrm{mg}\left[\mathrm{IrCl}_{2} \mathrm{Cp}^{*}\right]_{2}\right.$ and $100 \mathrm{mg}$ micro- or meso-CTF powder).

\subsection{Preparation of Pt@CTF@monolith}

Firstly, a solution of $0.01 \mathrm{~g} \mathrm{~K}_{2}\left[\mathrm{PtCl}_{4}\right]$ in $10 \mathrm{~mL} \mathrm{H}{ }_{2} \mathrm{O}$ was prepared. Next, the CTF-coated monolith was stirred overnight in this solution at $60^{\circ} \mathrm{C}$. Following this, the Pt exchanged
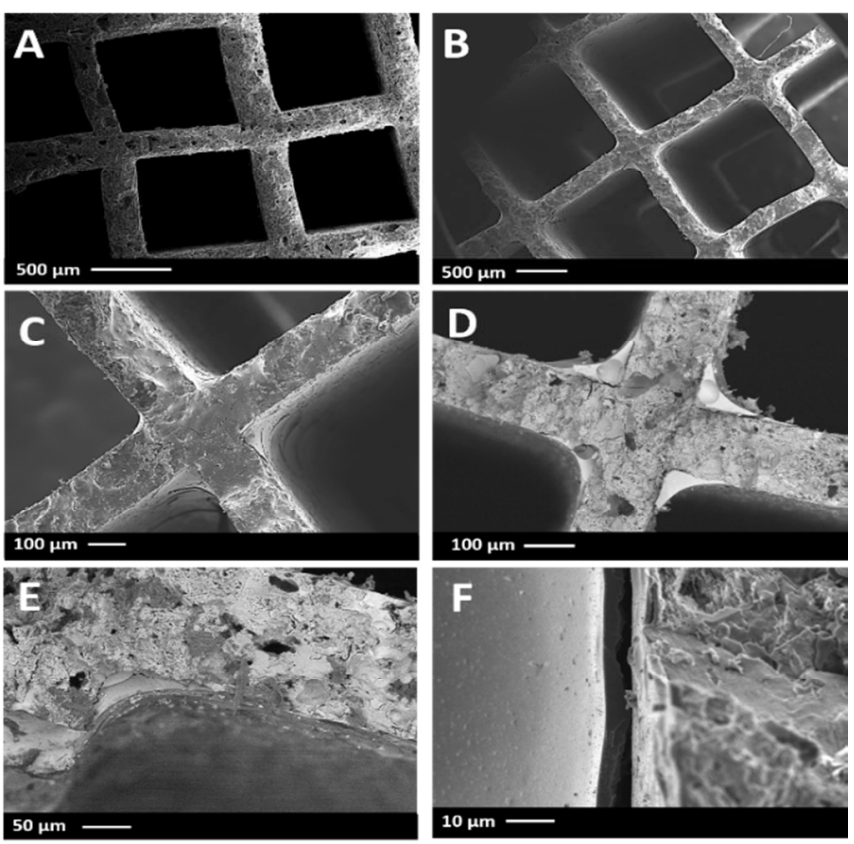

ACS Paragon Plus Environment 
monolith was washed in a $30 \mathrm{~mL}$ water. Finally, the sample was vacuum dried at $80{ }^{\circ} \mathrm{C}$ overnight. Coordination of $\mathrm{Pt}$ to the powder was performed as described elsewhere. ${ }^{15}$

Figure 1.- SEM micrographs of CTF@monolith. A: bare cordierite monolith, top view; B, C, D, E: CTF coated monolith, cross-sectional views; F: view on wall of a CTF coated monolith (left).

\subsection{Formic Acid Dehydrogenation}

The Ir@CTF@monolith catalyst samples with 0.045 mg Ir $(0.23$ mmol $)$ were tested in a monolith stirrer reactor configuration. To this end, the structured support was attached to a mechanical stirrer and placed in a $50 \mathrm{~mL}$ aqueous solution of $3 \mathrm{M}$ formic acid $(0.15 \mathrm{~mol})$. The vessel containing the reaction mixture was submerged in an oil bath and heated to the desired temperature of $80^{\circ} \mathrm{C}$ under continuous stirring. The reaction was carried out for $24 \mathrm{~h}$. For recycling the catalyst, the coated monolith was washed with water at $50{ }^{\circ} \mathrm{C}$ and dried in vacuum at $60^{\circ} \mathrm{C}$ overnight. The $\mathrm{Ir} @ \mathrm{CTF}$ powder $(50 \mathrm{mg})$ with $0.065 \mathrm{mg} \mathrm{Ir}(0.34 \mathrm{mmol})$ was tested as described elsewhere. ${ }^{13}$

\subsection{Methane to Methanol Oxidation}

Catalytic tests were carried out in a $45 \mathrm{ml}$ Titania grade 2 autoclave fitted with a Teflon insert in batch mode. The autoclave was filled with oleum $\left(30 \% \mathrm{SO}_{3}, 10 \mathrm{~mL}\right)$ and the catalyst $(\mathrm{CTF}+$ monolith) was fitted inside the Teflon insert in a Teflon holder that provides a clamp to fit the monolith on top and a magnetic bar on the bottom (Figure S6). The autoclave was closed and flushed with helium. The reactor was pressurized to 40 bar $\mathrm{CH}_{4}$ and heated to $180{ }^{\circ} \mathrm{C}$ at $2{ }^{\circ} \mathrm{C}$ $\min ^{-1}$. The reaction time was $2 \mathrm{~h}$, after which the autoclave was cooled down to room temperature. Depressurizing of the system was controlled by backpressure controller to avoid 
foaming of the reaction medium. Once depressurized and helium flushed, the autoclave was opened and the monolith was taken out of the reaction medium and the liquids were collected in a separate glass vial for analysis quantification. Before any recycling experiment, the monolith was previously washed and dried at $80{ }^{\circ} \mathrm{C}$ under reduced pressure. Once dry the procedure followed for recycling was identical to that described above.

\section{Results and Discussion}

In a previous work, when comparing the catalytic performance of Ir@CTF-polymer composite spheres in the dehydrogenation of formic acid, we observed a lower catalytic activity per Ir site (TOF) than that of the non-composite material. ${ }^{14}$ Similar observations have been made for other heterogenised CTF supported catalysts ${ }^{15}$ when comparing them to their homogeneous counterparts. This is usually attributed to diffusion limitations derived from heterogenisation. It is indeed straightforward to envisage that active site accessibility is easier for a dissolved homogeneous catalytic complex than that for a porous solid. In order to unravel differences in catalytic performance and to further improve the Ir-based catalyst utilisation, we have modified catalyst accessibility and mass transport at two different length scales. On the one hand, CTFs with two different pore architectures were synthesised: the one denoted as micro-CTF contains only micro-pores, while meso-CTF contains both micro- and meso-pores in a range from 1.5 to $10 \mathrm{~nm} \cdot{ }^{14,19-20}$ These materials differ in porosity and nitrogen content, while their chemical and thermal stability are alike. On the other hand, the performance of thin CTF coatings on a highly open support (i.e. a monolith) is compared with that of the bulk material (powder, Figure 2). 


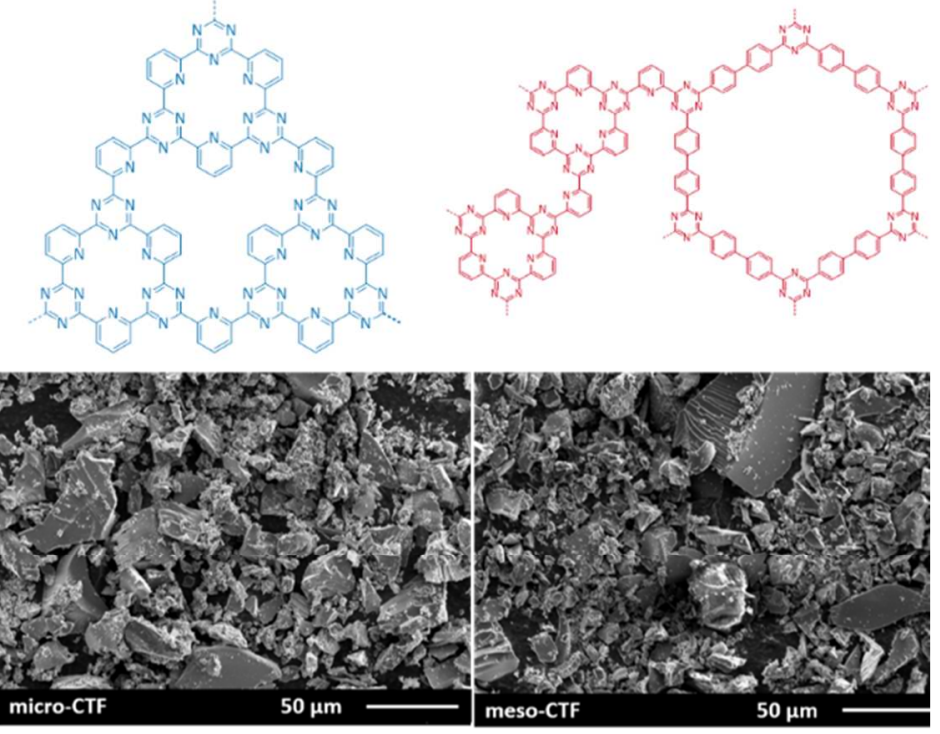

Figure 2.- top: Structures of micro-CTF (left) and meso-CTF (right); bottom: SEM micrograph of CTF powders (after crushing and reported washing procedure).

Monolithic structures are widely used in off-gas treatment, e.g. automotive exhaust gas purification $^{21}$ and de-NOx of power plant stack gases ${ }^{22}$. Monoliths are also considered attractive catalyst support alternatives compared to conventional carriers in other heterogeneous catalysis applications, including liquid-phase catalysis. ${ }^{23-26}$ Monoliths feature a high void fraction and large geometric surface area, which results in a large contact area between the catalyst and reactants and low-pressure drop under flow conditions. ${ }^{24}$ The most widely used monolith support material is based on cordierite $\left(2 \mathrm{MgO} \cdot 2 \mathrm{Al}_{2} \mathrm{O}_{3} \cdot 5 \mathrm{SiO}_{2}\right)$ and it contains a macro-porous wall structure. ${ }^{27-29}$ This macro-porous space may create an obstacle for applying a thin uniform layer of the catalyst, since it can lead to deposition of ineffective active phase within the macro-pores, where it is not accessible for substrates. ${ }^{30}$ In this work, this property was partially turned to our advantage; the cordierite porosity was found to be crucial to achieve adhesion of the CTF coatings. 
CTFs are typically synthesised in molten $\mathrm{ZnCl}_{2}$, which serves both as a solvent and trimerisation catalyst. The synthesis occurs at elevated temperatures, at which the CTF precursors, except $\mathrm{ZnCl}_{2}$, become volatile. Figure 3 summarises the synthesis protocol followed for the preparation of the supported CTFs: the cordierite monolith was impregnated with CTF precursors by filling the macro-porosity by using a low boiling point solvent (acetone). After acetone evaporation, the loaded monolith was placed in an ampoule and the polymerisation procedure was performed.

Figure 3.- Representation of the coating procedure steps

Since the macroporous monolith surface was homogeneously coated with zinc chloride, polymerisation of the evaporated monomers takes place selectively and right away on the surface of the support. The obtained films are in this way strongly attached to the cordierite surface (see Figure 1) and display excellent mechanical robustness during modification of the catalyst. Although the wall of the monoliths shows clearly a thin layer, thicker coatings are observed in the corners of the monolith channels. This relates to the capillary forces at the time of drying, which follows the acetone impregnation/exchange procedure inside of monolith. ${ }^{25}$

Additional experiments using a $\gamma-\mathrm{Al}_{2} \mathrm{O}_{3}$ monolith were not successful because of dissolution of the monolith during the $\mathrm{HCl}$ post-treatment step to remove $\mathrm{ZnCl}_{2}$. Although a coating could also be obtained using metal plates as dense supports, it was not mechanically rigid and was easily

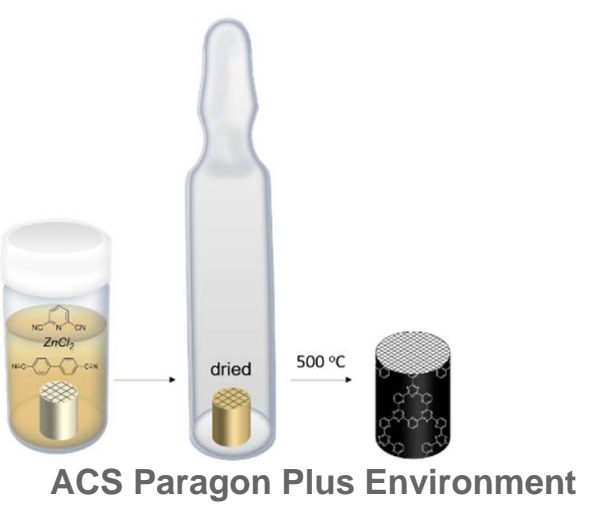


removed from the surface when handling the material. Therefore, we conclude that the macroporosity of the selected cordierite monolithic support indeed plays an important role, ,storing“ the precursors and $\mathrm{ZnCl}_{2}$ within its structure and, thus, serving in anchoring the $\mathrm{CTF}$ coating.

Since the proof of the pudding is in the eating, to demonstrate that the coatings observed in Figure 1 matter indeed the envisaged CTF, different characterisation techniques were applied. Thermo-gravimetric analysis in air (Figure S1) indicates a clear weight loss in the CTF@monolith sample at a temperature similar to that of the decomposition/oxidation of the $\mathrm{CTF}$ powder at around $500^{\circ} \mathrm{C}$. From this analysis, a CTF coating of about 15 wt.\% was calculated for the CTF@cordierite material. Having this in mind, $\mathrm{N}_{2}$ adsorption isotherms using the entire CTF@monolith piece were performed (nitrogen adsorption of bare cordierite monolith was found to be negligible). The obtained values were normalised to the mass of CTF in the CTF@monolith (Figure S2). The total loading of CTF per monolith is in the mg range. Therefore, the associated error to the measurement of the micro-CTF@monolith isotherms is expected to be somewhat high and thus it causes a mismatch when compared to the isotherm of the micro-CTF powder. In contrast, in the case of meso-CTF@monolith, the isotherms for the powder and the monolith are fairly identical. The nature of the nitrogen species from XPS

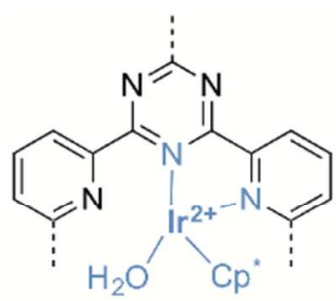

Ir@CTF

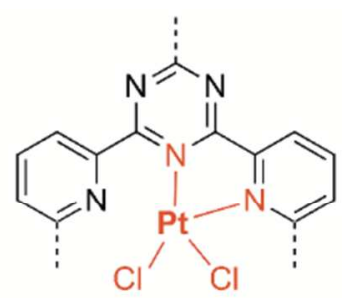

Pt@CTF

analysis was found to be identical in CTF and CTF@monolith (Figure S4). 
Table 1 TOFs of the hydrogen production from formic acid ${ }^{[a]}$

The results described above present a compelling indication that the coating on the monolith bears the same nature as CTF powder. Therefore, the iridium catalyst active in hydrogen production from formic acid was anchored to the CTF-coating in a similar fashion as it was done

Figure 4.- Structures of the envisaged Ir@CTF (left) and Pt@CTF (right) catalysts.

to the powder or spheres (Figure 4). ${ }^{13-14}$ Here, EDX analysis confirms that iridium was successfully coordinated to the bipyridinic moieties (Figure S4). The obtained catalyst is denoted as Ir@CTF@monolith. The performance of both micro- and meso-porous Ir@CTF@monoliths was tested in formic acid dehydrogenation and compared with that of powder samples with the same

metal loading (Table 1). All experiments were performed at identical conditions - 3M aqueous formic acid solution, $80^{\circ} \mathrm{C}$, and similar stirring speeds. During recycling, the catalyst was stored under ambient conditions. 


\begin{tabular}{|c|c|c|}
\hline Entry & Sample & $T O F\left[\mathrm{~h}^{-1}\right]^{[\mathrm{b}]}$ \\
\hline 1 & Ir@micro-CTF@monolith ${ }^{[\mathrm{c}]}$ & $156300 \pm 160$ \\
\hline 2 & Ir@meso-CTF@monolith ${ }^{[\mathrm{c}]}$ & $207200 \pm 180$ \\
\hline 3 & $\mathrm{Ir} @{\operatorname{micro}-\mathrm{CTF}^{[\mathrm{d}]}}^{[}$ & $73800 \pm 110$ \\
\hline 4 & $\mathrm{Ir} @$ meso-CTF $^{[\mathrm{e}]}$ & $105100 \pm 125$ \\
\hline \multicolumn{3}{|c|}{$\begin{array}{l}\text { [a] } 50 \mathrm{ml} 3 \mathrm{M} \text { aqueous formic acid solution; }{ }^{[\mathrm{b}]} \text { calculated from }{ }^{1} \mathrm{H} \text { NMR analysis of formic } \\
\text { acid; }{ }^{[\mathrm{c}]} 0.045 \mathrm{mg} \operatorname{Ir}(0.23 \mu \mathrm{mol}) ;{ }^{[\mathrm{d}]} 0.067 \mathrm{mg} \operatorname{Ir}(0.34 \mu \mathrm{mol}) ;{ }^{[\mathrm{e}]} 0.097 \mathrm{mg} \operatorname{Ir}(0.50 \mu \mathrm{mol}) .\end{array}$} \\
\hline
\end{tabular}

From the catalytic results shown in Table 1, it is clear that porosity has an influence on catalyst performance. Comparison of the fully microporous version of the powder catalyst (entry 3 ) to its micro-mesoporous analogue (entry 4) showed that meso-porosity improved the catalytic activity by circa $30 \%$. While this activity trend was preserved when comparing the two monolith catalysts (entry $1 v s$ 2), it is obvious that by applying a coating onto a monolith an overall activity improvement of almost a $100 \%$ (entry 1 vs 3 and 2 vs 4 ) is observed. We attribute these improvements to both the shorter diffusion path-length in the monolith coating (compare figure 2 (crushed powder) and figure 1 (coating on the monolith)) and to the improved mass transfer from the liquid to the coated channel wall. Nevertheless, application of catalyst performance test criteria indicates that the highly active Ir catalyst operates at the onset of mass transport interference. 
Another clear advantage of the monolithic catalysts is that recycling and stability testing becomes straightforward. Figure 5 shows the observed performance for both monoliths over 5 consecutive catalytic runs. In both cases the first run displayed a slightly lower activity. We attribute this improvement to the occurrence of ligand exchange: most probably, the weakly coordinating triflate anion is replaced by formates in the first catalytic cycle. This was confirmed by EDX analysis, where fluorine is homogeneously distributed in the fresh catalyst and not detectable any more after several uses. Last but not least, it is worth highlighting that the TOFs obtained for the monolithic systems are the highest among those reported in the literature for heterogeneous systems for this reaction. ${ }^{16,31-36}$

Figure 5.- $T O F$ s of Ir catalyst for several catalytic runs of hydrogen production from formic acid: Ir@micro-CTF@monolith (blue); Ir@meso-CTF@monolith (red); Ir@micro-CTF (light

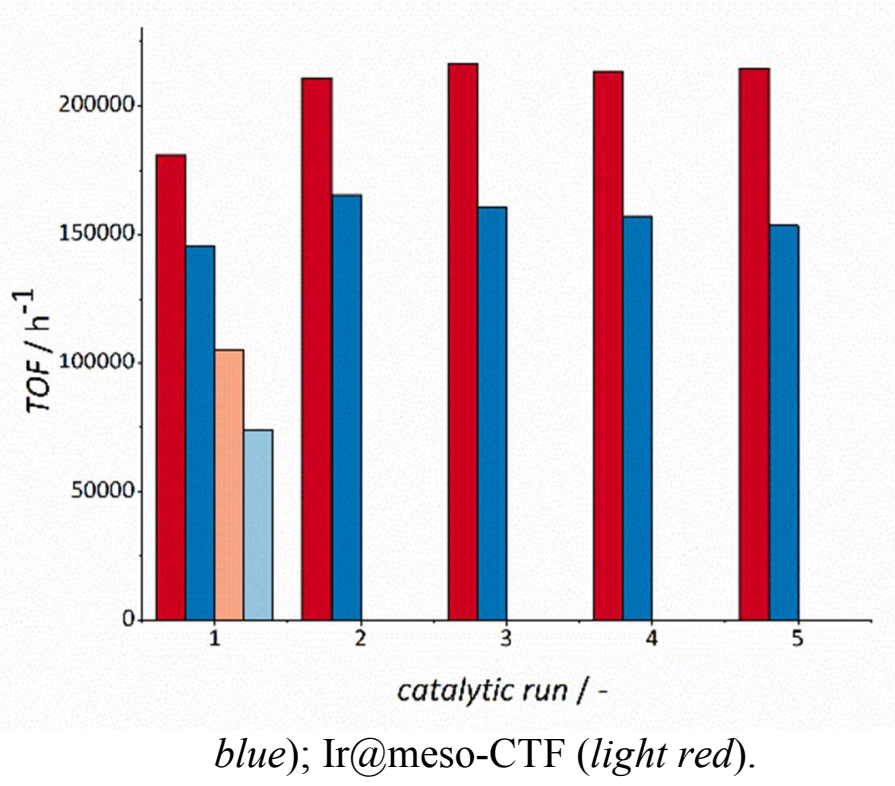

Driven by these results and inspired by the pioneering work of Schüth et $a l^{37}$ on the immobilisation of the well-known Periana catalyst, we tested our monolithic supports in a more 
challenging reaction: the selective partial oxidation of methane to methanol in oleum. Based on chemistry first developed by Shilov, ${ }^{38}$ in the Catalytica/Periana System, a methane molecule is directly oxidised to methyl bisulfate when performing the reaction in oleum using a (bpym) $\mathrm{PtCl}_{2}$ complex as catalyst. ${ }^{37}$ The reaction proceeds at moderate temperatures $\left(c a .200{ }^{\circ} \mathrm{C}\right)$ and high methane pressure (ca. 40 bar). Recently, tetrachloroplatinate $\left(\mathrm{K}_{2}\left[\mathrm{PtCl}_{4}\right]\right)$ was found to be active for the same reaction, with TOFs of $25000 \mathrm{~h}^{-1}$, more than 3 orders of magnitude higher activity than that for (bpym) $\mathrm{PtCl}_{2}{ }^{39}$ Years after the original work of Periana, Schüth et al. developed a heterogeneous counterpart by using a CTF as support (Figure 4) in a similar fashion to Ir, vide supra. $^{15}$ The Pt@CTF solid was found to be an active and recyclable catalyst, which is remarkable under the given reaction conditions. We, therefore, coordinated $\mathrm{K}_{2}\left[\mathrm{PtCl}_{4}\right]$ to both micro- and meso-CTF coated monoliths. As in the case of the Ir complex, Pt was well dispersed over the shaped material (Figure S5). The monolithic pieces were attached within a Teflon holder (Figure S6) and submerged in fuming sulfuric acid $\left(30 \% \mathrm{SO}_{3}\right)$ under 40 bar methane pressure. An unsupported version of the catalyst using microporous CTF with a similar Pt loading was also prepared and tested under slurry operation. Catalytic results are summarised in Table 2. While the Pt@micro-CTF@monolith preserved its integrity after the catalytic cycle, the mesoporous material containing monolith was seriously damaged under reaction conditions with a clear leaching to the oleum solution. We tentatively attributed the lower stability of the mesoporous coating to the higher accessibility, potentially leading to $\mathrm{H}_{2} \mathrm{SO}_{4}$ intercalation and exfoliation under reaction conditions. Nevertheless, this sample attained a decent number of turnovers after 2 h $(T O N=2230)$. The Pt@micro-CTF@monolith appeared intact after 2 h under reaction conditions, attaining more than 
Table 2. TONs of the production of methanol by methane oxidation ${ }^{\lfloor\mathrm{a}\rfloor}$

\begin{tabular}{|c|c|c|c|}
\hline Entry & Sample & $\begin{array}{l}\text { Final } \mathrm{MeSO}_{4} \mathrm{H} \\
\text { concentration } \\
{[\mathrm{M}]}\end{array}$ & $T O N^{[b]}$ \\
\hline 1 & $\begin{array}{l}\text { Pt@meso- } \\
\text { CTF@monolith }\end{array}$ & 0.34 & $2230 \pm 25$ \\
\hline 2 & $\begin{array}{l}\text { Pt@micro- } \\
\text { CTF@monolith }\end{array}$ & 0.64 & $5160 \pm 30$ \\
\hline 3 & $\mathrm{Pt} @$ micro-CTF $^{\lfloor\mathrm{e}\rfloor}$ & 0.01 & $60 \pm 10$ \\
\hline
\end{tabular}

5000 turnovers within $2 \mathrm{~h}$. This activity is a factor two higher than that observed for its powdered counterpart. Once again, this demonstrates the advantages of catalyst structuring. ${ }^{28-29}$ The obtained values showed that Pt@CTF@monoliths outperform the originally published Periana system with TOFs of $10^{-2} \mathrm{~s}^{-1} 37$ as well as Pt@CTF system of Schüth (TON of 426 after $\left.2.5 \mathrm{~h}\right){ }^{15}$ Although these values do not reach the highest reported TOF of $c a .25000 \mathrm{~h}^{-1}$ for this system reported in another work of Schüth under optimised conditions, ${ }^{39}$ it opens up motivation for catalyst engineering at different lenghscales.

\section{Conclusions}

In summary, by applying a new synthetic protocol, CTF based stable films could be successfully deposited on the surface of cordierite monoliths. Extensive characterisation demonstrates that these coatings contain similar properties to those of the material in powder form. After coordination of an iridium complex, the obtained catalyst Ir@CTF@monolith was employed in the reaction of hydrogen production from formic acid. The obtained TOF is $>200$ $000 \mathrm{~h}^{-1}$ in case of the Ir@meso-CTF@monolith. The catalyst was stable in ambient air and no 
pre-treatment was required prior to utilisation.Pt@micro-CTF@monolith shows TONs of over 5000 after $2 \mathrm{~h}$ in the direct activation of methane. These results demonstrated that CTF based catalysts can be further engineered by optimisation at different length-scales (the micro-, meso-, and macro-level) alleviating internal and external mass transport limitations. ${ }^{28}$ ASSOCIATED CONTENT

\title{
Supporting Information.
}

Characterisation of CTF coating and the catalysts with TGA, Nitrogen physisorption, TGA, XPS, SEM

\author{
AUTHOR INFORMATION \\ Jorge Gascon, Anastasiya V. Bavykina \\ jorge.gascon@kaust.edu.sa, anastasiya.bavykina@ kaust.edu.sa
}

\section{Author Contributions}

All authors have given approval to the final version of the manuscript. .

\section{REFERENCES}

1. Kuhn, P.; Antonietti, M.; Thomas, A., Porous, Covalent Triazine-Based Frameworks Prepared by Ionothermal Synthesis. Angew. Chem. Int. Ed. 2008, 47, 3450-3453.

2. Kuhn, P.; Thomas, A.; Antonietti, M., Toward Tailorable Porous Organic Polymer Networks: A High-Temperature Dynamic Polymerization Scheme Based on Aromatic Nitriles. Macromolecules 2009, 42, 319-326. 
3. Bhunia, A.; Esquivel, D.; Dey, S.; Fernandez-Teran, R.; Goto, Y.; Inagaki, S.; Van Der Voort, P.; Janiak, C., A photoluminescent covalent triazine framework: CO2 adsorption, lightdriven hydrogen evolution and sensing of nitroaromatics. J. Mater. Chem. A 2016, 4, 1345013457.

4. Bhunia, A.; Boldog, I.; Moller, A.; Janiak, C., Highly stable nanoporous covalent triazine-based frameworks with an adamantane core for carbon dioxide sorption and separation. J. Mater. Chem. A 2013, 1, 14990-14999.

5. Hug, S.; Stegbauer, L.; Oh, H.; Hirscher, M.; Lotsch, B. V., Nitrogen-Rich Covalent Triazine Frameworks as High-Performance Platforms for Selective Carbon Capture and Storage. Chem. Mater 2015, 27, 8001-8010.

6. Tao, L.; Niu, F.; Wang, C.; Liu, J.; Wang, T.; Wang, Q., Benzimidazole functionalized covalent triazine frameworks for CO2 capture. J. Mater. Chem. A 2016, 4, 11812-11820.

7. Wang, K.; Huang, H.; Liu, D.; Wang, C.; Li, J.; Zhong, C., Covalent Triazine-Based Frameworks with Ultramicropores and High Nitrogen Contents for Highly Selective CO2 Capture. Environ. Sci. Technol. 2016, 50, 4869-4876.

8. Iwase, K.; Yoshioka, T.; Nakanishi, S.; Hashimoto, K.; Kamiya, K., Copper-Modified Covalent Triazine Frameworks as Non-Noble-Metal Electrocatalysts for Oxygen Reduction. Angew. Chem. Int. Ed. 2015, 54, 11068-11072.

9. Kamiya, K.; Kamai, R.; Hashimoto, K.; Nakanishi, S., Platinum-modified covalent triazine frameworks hybridized with carbon nanoparticles as methanol-tolerant oxygen reduction electrocatalysts. Nature Comm. 2014, 5, 5040. 
10. Yoshioka, T.; Iwase, K.; Nakanishi, S.; Hashimoto, K.; Kamiya, K., Electrocatalytic Reduction of Nitrate to Nitrous Oxide by a Copper-Modified Covalent Triazine Framework. $J$. Phys. Chem. C 2016, 120, 15729-15734.

11. Bi, J.; Fang, W.; Li, L.; Wang, J.; Liang, S.; He, Y.; Liu, M.; Wu, L., Covalent TriazineBased Frameworks as Visible Light Photocatalysts for the Splitting of Water. Macromol. Rapid Commun. 2015, 36, 1799-1805.

12. Jiang, X.; Wang, P.; Zhao, J., 2D covalent triazine framework: a new class of organic photocatalyst for water splitting. J. Mater. Chem. A 2015, 3, 7750-7758.

13. Bavykina, A. V.; Goesten, M. G.; Kapteijn, F.; Makkee, M.; Gascon, J., Efficient production of hydrogen from formic acid using a Covalent Triazine Framework supported molecular catalyst. ChemSusChem 2015, 8, 809-812.

14. Bavykina, A. V.; Rozhko, E.; Goesten, M. G.; Wezendonk, T.; Seoane, B.; Kapteijn, F.; Makkee, M.; Gascon, J., Shaping Covalent Triazine Frameworks for the Hydrogenation of Carbon Dioxide to Formic Acid. ChemCatChem 2016, 8, 2217-2221.

15. Palkovits, R.; Antonietti, M.; Kuhn, P.; Thomas, A.; Schüth, F., Solid Catalysts for the Selective Low-Temperature Oxidation of Methane to Methanol. Angew. Chem. Int. Ed. 2009, 48, 6909-6912.

16. Hausoul, P. J. C.; Broicher, C.; Vegliante, R.; Göb, C.; Palkovits, R., Solid Molecular Phosphine Catalysts for Formic Acid Decomposition in the Biorefinery. Angew. Chem. Int. Ed. 2016, 55, 5597-5601. 
17. Pilaski, M.; Artz, J.; Islam, H.-U.; Beale, A. M.; Palkovits, R., N-containing covalent organic frameworks as supports for rhodium as transition-metal catalysts in hydroformylation reactions. Micropor. Mesopor. Mat. 2016, 227, 219-227.

18. Artz, J.; Palkovits, R., Base-Free Aqueous-Phase Oxidation of 5-Hydroxymethylfurfural over Ruthenium Catalysts Supported on Covalent Triazine Frameworks. ChemSusChem 2015, 8, 3832-3838.

19. Dey, S.; Bhunia, A.; Breitzke, H.; Groszewicz, P. B.; Buntkowsky, G.; Janiak, C., Two linkers are better than one: enhancing $\mathrm{CO} 2$ capture and separation with porous covalent triazinebased frameworks from mixed nitrile linkers. J. Mater. Chem. A 2017, 5, 3609-3620.

20. Dey, S.; Bhunia, A.; Boldog, I.; Janiak, C., A mixed-linker approach towards improving covalent triazine-based frameworks for $\mathrm{CO} 2$ capture and separation. Micropor. Mesopor. Mat. 2017, 241, 303-315.

21. Cybulski, A.; Moulijn, J. A., Structured catalysts and reactors. 2nd ed. ed.; Taylor \& Francis: Boca Raton :, 2006.

22. Nova, I.; Beretta, A.; Groppi, G.; Lietti, L.; Tronconi, E.; Forzatti, P., Monolithic catalysts for NOx removal from stationary sources. In Structured Catalysts and Reactors, Cybulski, A.; Moulijn, J. A., Eds. 2005; pp 171-214.

23. Nijhuis, T. A.; Beers, A. E. W.; Vergunst, T.; Hoek, I.; Kapteijn, F.; Moulijn, J. A., Preparation of monolithic catalysts. Catal. Rev. 2001, 43, 345-380.

24. Vergunst, T.; Linders, M. J. G.; Kapteijn, F.; Moulijn, J. A., CARBON-BASED MONOLITHIC STRUCTURES. Catal. Rev. 2001, 43, 291-314. 
25. Pérez-Cadenas, A. F.; Kapteijn, F.; Moulijn, J. A., Tuning the morphology of monolith coatings. Appl. Catal., A. 2007, 319, 267-271.

26. Sandee, A. J.; Ubale, R. S.; Makkee, M.; Reek, J. N. H.; Kamer, P. C. J.; Moulijn, J. A.; Leeuwen, P. W. N. M. v., ROTACAT: A Rotating Device Containing a Designed Catalyst for Highly Selective Hydroformylation. Adv. Synth. Catal. 2001, 343, 201-206.

27. Banús, E. D.; Milt, V. G.; Miró, E. E.; Ulla, M. A., Catalytic coating synthesized onto cordierite monolith walls. Its application to diesel soot combustion. Appl. Catal., B 2013, 132$133,479-486$.

28. Kapteijn, F.; Heiszwolf, J. J.; Nijhuis, T. A.; Moulijn, J. A., Monoliths in multiphase catalytic processes - Aspects and prospects. Cattech 1999, 3, 24-41.

29. Gascon, J.; van Ommen, J. R.; Moulijn, J. A.; Kapteijn, F., Structuring catalyst and reactor - an inviting avenue to process intensification. Catal. Sci. Tech. 2015, 5, 807-817.

30. Crezee, E.; Kooyman, P. J.; Kiersch, J.; Sloof, W. G.; Mul, G.; Kapteijn, F.; Moulijn, J. A., Dispersion and Distribution of Ruthenium on Carbon-Coated Ceramic Monolithic Catalysts Prepared by Impregnation. Catal. Lett. 2003, 90, 181-186.

31. Zhang, S.; Metin, Ö.; Su, D.; Sun, S., Monodisperse AgPd Alloy Nanoparticles and Their Superior Catalysis for the Dehydrogenation of Formic Acid. Angew. Chem. Int. Ed. 2013, 52, 3681-3684.

32. Cai, Y.-Y.; Li, X.-H.; Zhang, Y.-N.; Wei, X.; Wang, K.-X.; Chen, J.-S., Highly Efficient Dehydrogenation of Formic Acid over a Palladium-Nanoparticle-Based Mott-Schottky Photocatalyst. Angew. Chem. Int. Ed. 2013, 52, 11822-11825. 
33. Lee, J. H.; Ryu, J.; Kim, J. Y.; Nam, S.-W.; Han, J. H.; Lim, T.-H.; Gautam, S.; Chae, K. H.; Yoon, C. W., Carbon dioxide mediated, reversible chemical hydrogen storage using a Pd nanocatalyst supported on mesoporous graphitic carbon nitride. J. Mater. Chem. A 2014, 2, 9490-9495.

34. Wang, Z.-L.; Yan, J.-M.; Ping, Y.; Wang, H.-L.; Zheng, W.-T.; Jiang, Q., An Efficient CoAuPd/C Catalyst for Hydrogen Generation from Formic Acid at Room Temperature. Angew. Chem. Int. Ed. 2013, 52, 4406-4409.

35. Koh, K.; Jeon, M.; Chevrier, D. M.; Zhang, P.; Yoon, C. W.; Asefa, T., Novel nanoporous N-doped carbon-supported ultrasmall Pd nanoparticles: Efficient catalysts for hydrogen storage and release. Appl. Catal., B.

36. Zhang, W.; Huang, H.; Li, F.; Deng, K.; Wang, X., Palladium nanoparticles supported on graphitic carbon nitride-modified reduced graphene oxide as highly efficient catalysts for formic acid and methanol electrooxidation. J. Mater. Chem. A 2014, 2, 19084-19094.

37. Periana, R. A.; Taube, D. J.; Gamble, S.; Taube, H.; Satoh, T.; Fujii, H., Platinum Catalysts for the High-Yield Oxidation of Methane to a Methanol Derivative. Science 1998, 280, 560.

38. Shilov, A. E.; Shul'pin, G. B., Activation of C-H Bonds by Metal Complexes. Chem. Rev. 1997, 97, 2879-2932.

39. Zimmermann, T.; Soorholtz, M.; Bilke, M.; Schüth, F., Selective Methane Oxidation Catalyzed by Platinum Salts in Oleum at Turnover Frequencies of Large-Scale Industrial Processes. JACS 2016, 138, 12395-12400. 


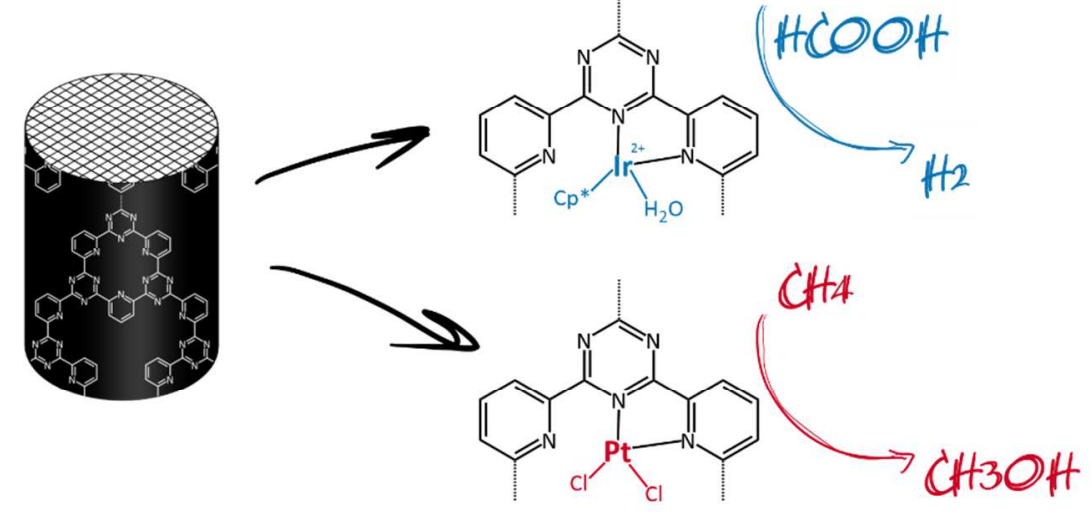

